\title{
THE ARITHMETICAL MACHINE ZERO + 1 IN MATHEMATICS LABORATORY: INSTRUMENTAL GENESIS AND SEMIOTIC MEDIATION
}

\author{
Michela Maschietto \\ Department of Education and Human Science \\ University of Modena e Reggio Emilia - IT \\ michela.maschietto@unimore.it
}

\begin{abstract}
This paper presents the analysis of two teaching experiments carried out in the context of the mathematics laboratory in a primary school (grades 3 and 4) with the use of the pascaline Zero +1 , an arithmetical machine. The teaching experiments are analysed by coordinating two theoretical frameworks, i.e. the instrumental approach and the Theory of Semiotic Mediation. The paper focuses on the analysis of the semiotic potential of the pascaline and students' instrumental genesis, on the functions of schemes and gestures of usage.
\end{abstract}

KEY WORDS: arithmetic, artefact, instrumental genesis, mathematics laboratory, pascaline, semiotic mediation

\section{INTRODUCTION}

Mankind has historically constructed and used tools to accomplish tasks (Norman, 1993; Vygotsky, 1934/1990). This use has both historical and epistemological roots, as well as cognitive ones. Tools for the construction of perspective drawings, for instance, supported not only artists in their work, but also mathematicians in deriving theoretical treatises (Bartolini \& Borba, 2010). The role of tools is a key element in Vygostkian psychology, to which the Theory of Semiotic Mediation considered in this paper refers. On the other hand, the analysis of the human activity with artefacts is a central topic in instrumental approaches, for instance in cognitive ergonomics concerning professional develop- ment (Rabardel, 1995/2002). Interest in the use of tools for teaching and learning mathematics is growing more and more. From a historical perspective, discussions about the use of tools in mathematics education have been present since the end of eighteenth century within the works of educators and mathematicians (Giacardi, 2012). Nowadays, several experimental projects in mathematics education study the introduction and integration of tools, in particular from digital technologies (Hoyles \& Lagrange, 2010), at any school level. This paper focuses on the use of a tool in order to mediate mathematical meanings. However, this tool is not a digital tool but a manipulative one: the Zero +1 arithmetical machine, called ,"pascaline". It is meant for writing numbers and making arithmetical operations, but also studying some properties of natural numbers. The teaching experiments considered in this paper were carried out within the Theory of Semiotic Mediation in mathematics education (Bartolini Bussi \& Mariotti, 2008), even if the development of instrumental approaches in mathematics education (Artigue, 2002; Trouche, 2004) were also taken into account. The aim of this study is to deepen the understanding of the relationships between these two different theoretical frameworks (following Maschietto \& Trouche, 2010), through the analysis of teaching experiments focused on the use of manipulatives, like the pascaline.

This article consists of four sections. In the first one, the idea of mathematics laboratory is outlined and the arithmetical machine is described. The second section presents the theoretical background; the third and fourth sections contain the adopted methodology and the analysis of the teaching experiments. Finally, some elements for further discussion are drawn.

\section{MATHEMATICS LABORATORY AND TOOLS}

From cultural and didactical points of view, the use of manipulatives can be considered an element characterising the mathematics laboratory since the first studies about the use of tools in mathematical teaching and learning (Maschietto \& Trouche, 2010; Giacardi, 2012). In some institutional documents concerning mathematics curriculum in Italian schools, mathematics laboratory is considered as a didactical methodol- ogy, based on various and structured activities, that aims at constructing mathematical meanings (AA.VV. UMI, 2004). On the one hand, this construction is directly related to the use of tools in mathematics; on the other hand, it is based on the interactions among the subjects (students and teacher) working together. Thus, both 
theoretical and technical topics are present in the mathematics laboratory. According to Chiappini \& Reggiani (2004), activities in mathematics laboratory are "finalised to the construction of the experiential base which is necessary for the appropriation of the mathematical meanings" (Ibidem, p.3). From this point of view, a mathematics laboratory can be considered as a metaphorical place where students' conceptualisation and reflexive thinking take place.

In this paper, we consider an implementation of the idea of mathematics laboratory with the pascaline Zero+1 (Fig. 1a). This is a plastic tool, inspired by the mechanical calculators like the famous Pascaline designed by Blaise Pascal (1623, 1662; Fig. 1c). It was named ,pascaline, by students who used it (Savioli, 2005; Maschietto \& Ferri, 2007; Maschietto, 2011). In the following, the machine is indifferently referred to as "pascaline" or "Zero+1".

The pascaline is composed of a base, with a gear train (five wheels): three yellow wheels (A, B and C; Fig. 1b) at the bottom and two orange wheels (E and D; Fig. 1b) at the top. Each wheel has ten teeth; the Arabic numerals are written on each tooth of each yellow wheel, while a mauve arrow is integral with each orange wheel. Below the yellow wheels, small red pyramidal prisms ("small red triangles") indicate a tooth; there are red movable commas (decimal point) in the bottom-right corner and holes for it between the red triangles. The wheels can move clockwise or anticlockwise; wheels A, B and C are not directly engaged, while D and E are auxiliary wheels to transmit motion. This machine works as a counter in base ten. When wheel A (or B) has turned by a complete rotation, wheel D (or E) makes wheel B (or C) move one step forward (Fig. 1b).

\section{THEORETICAL BACKGROUND}

In their theoretical approach to mathematics laboratories, Maschietto \& Trouche (2010) adopt two theoretical frameworks, the instrumental approach (Rabardel, 1995/2002) and the Theory of Semiotic Mediation (Bartolini Bussi \& Mariotti, 2008). They develop the idea of coordinating between them within the approach of networking strategies (Prediger, Bikner-Ahsbahs \& Arzarello, 2008) by the analysis of some examples concerning the implementation of mathematics laboratory sessions, with classical and digital tools. This paper aims to achieve deeper insight into how these frameworks coordinate at the levels of task design and analysis of students' resolution processes.
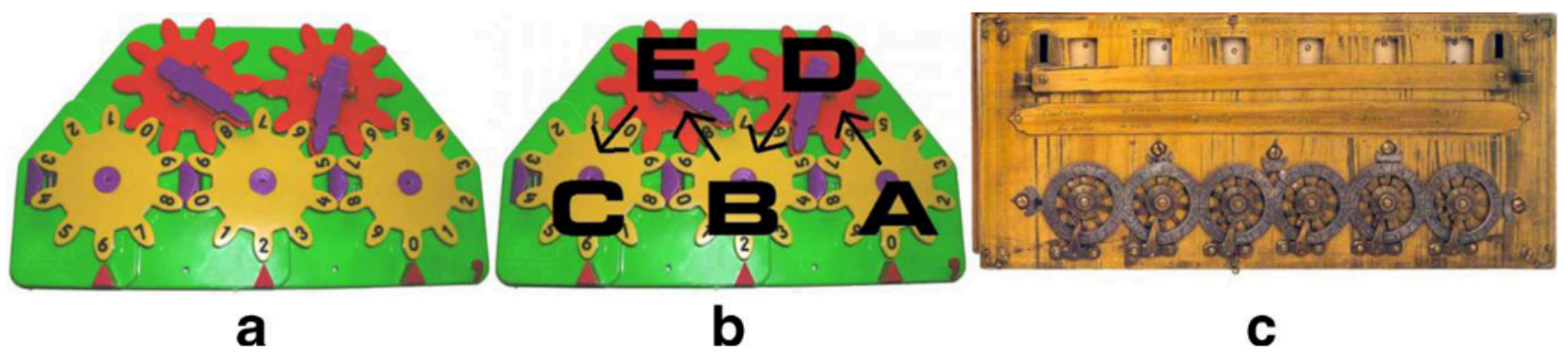

Figure 1. Arithmetical machine Zero+1 (on the left and in the centre), pascaline by Blaise Pascal (1642, on the right)

In this section, these two frameworks will be outlined. Note that the instrumental approach is considered as a cognitive approach, while the Theory of Semiotic Mediation furnishes a didactical structure of activities.

\section{Instrumental Approach}

As stressed by Drijvers, Kieran and Mariotti (2010), the linguistic expression "instrumental approach" refers to several acceptances in mathematics education. In this paper, we refer to the instrumental approach following the definition by Rabardel (1995/2002) and Vérillon \& Rabardel (1995) as applied in mathematics education by Trouche (2004) and Trouche \& Drijvers (2010), paying increasing attention to the teacher's role and to management of tools in the classroom (for instance, instrumental orchestration).

Rooted in research works on the use of tools in human activity, the instrumental approach pays attention to the distinction between artefact and instrument. The former is a material or abstract object, already produced by human activity. The latter is a mixed entity containing components from the artefact and components from user's utilisation schemes that are defined as "stable and structured elements in the user's activities and actions" (Rabardel, 1995/2002, p. 65). Utilisation schemes have both a private and a social dimension (Béguin \& 
Rabardel, 2000): they can result from a personal and private construction of the user and/or from the appropriation of social schemes formed by a collectivity. The process leading to the development of the instrument to perform specific tasks is called instrumental genesis. It is composed of two kinds of processes: instrumentation and instrumentalisation. The former is relative to the emergence and evolution of utilisation schemes related to performing a set of tasks by the means of the artefact; the latter concerns the evolution of the artefact, from the emergence of its components until permanent change in its structure. From the point of view of learning, the distinction between these two kinds of process can be relevant if it allows to characterise which cognitive processes are activated with respect to the kinds of tasks that are proposed. Utilisation schemes, developed during the activities, are of particular interest because they are strongly related to the construction of knowledge. From this perspective, Rabardel's analysis of constituents and functions of the utilisation schemes (Rabardel, 1995/2002) seems to apply well. He distinguishes between two constituents: usage schemes, which are related to the management of characteristics and specific properties related to the artefact; and instrumentmediated action schemes (instrumented action schemes in this text), oriented to carry out specific tasks. Relevantly, what defines a scheme to be a usage scheme or an instrumented action scheme does not refer to a property of the scheme itself, but instead to its status in the subject's activity. Rabardel also detects three main functions: a pragmatic function (focused on transforming the situation and obtaining results); a heuristic function (that orients and controls the activity, it allows the agent to anticipate and plan actions) and an epistemic function (focused on understanding situations, it allows the agent to understand what he is doing). Identification of these functions of utilisation schemes could be relevant to the learning process, as it could highlight that the three functions have to be solicited, in particular the epistemic function.

\section{Theory of Semiotic Mediation}

The Theory of Semiotic Mediation (TSM) has been elaborated and applied to mathematics education by Bartolini Bussi \& Mariotti (2008) within a Vygostkian perspective. This section contains three elements of that frame- work: the definition of a tool of semiotic mediation, the notion of semiotic potential of an artefact and the didactical structure of tasks with artefacts.

Bartolini Bussi and Mariotti adopt Hasan's definition of mediation (2005), which refers to a complex process involving (1) teacher as mediator; (2) something that is mediated (i.e. a piece of mathematical knowledge); (3) students for whom the mediation has an effect; and (4) circumstances, as tasks on artefacts and places as the mathematics laboratory. The authors study the process of mediation and the relationships among those four components. They claim the teacher uses an artefact as a tool of semiotic mediation when he/she acts as a cultural mediator using the artefact to mediate mathematical content to the students. A fundamental element of this framework is that every activity with an artefact fosters the production of signs (semiotic activity) that may be used by the teacher to construct and/or consolidate mathematical meanings evoked by usage of the artefact; in particular, "a main characteristic of these signs is that their meaning maintains a strong link with the operations accomplished" (Bartolini Bussi \& Mariotti, 2008, p.753). If a link is established between use and meanings, then the choice of which artefact is to be used represents the starting point of the whole didactic process of semiotic mediation. It is made by the teacher according to the educational aims (related to the second component of the mediation) and the analysis of the semiotic potential of the artefact.

The study of the semiotic potential of an artefact is an original element of the Theory of Semiotic Mediation. It furnishes an outline to analyse artefacts for learning and teaching mathematics. The semiotic potential is defined as the double semiotic link established between the artefact and personal meanings, emerging in students' mind from its use to accomplish a task (that has to be accessible for students), and, the artefact and mathematical meanings evoked by its use and recognisable as mathemat- ics by an expert on the other hand. In this kind of analysis, Bartolini Bussi and Mariotti exploit the notion of utilisation schemes (Mariotti, 2012). In the following section, the analysis of semiotic potential for the pascaline will be presented.

The Theory of Semiotic Mediation offers the didactic organisation of the work with artefacts for students and teacher. The process of semiotic mediation is grounded in a specific structure of activities called the "didactical cycle": (1) activities with the artefact usually in small group, that promote the emergence of signs (words, sketches, gestures, ...) in relation to its use; (2) individual written production of signs (drawings, writing, ....); (3) collective moments leading to social production of signs, where mathematical discussion is the fundamental didactic strategy. The TSM also specifies the role of the teacher. First, she/he has to plan specific tasks with the artefact for students in order to foster a semiotic activity, whose results are usually "situated texts". These hybrid texts contain elements from the concrete situation and some mathematical elements, but also new expressions that arise from the activities with the artefact. Then, the teacher guides the transformation and evolution of these situated texts into mathematical texts (representative of the meanings evoked by the artefact), through a sequence of tasks structured within didactical cycles. The structure of the teaching 
experiments within mathematics laboratory discussed in this paper is consistent with the organisation of didactical cycles.

\section{Research Questions}

This paper aims to deepen the contribution of two theoretical frameworks in characterising the mathematics laboratory methodology (following Maschietto \& Trouche, 2010), taking into account cognitive, epistemological and didactical components. Our research focuses on the one hand on identifying the contributions of the instrumental approach in analysing the students' cognitive processes when using an artefact within the semiotic mediation; on the other hand, on how the attention to semiotic activity can enrich the identification of utilisation schemes and their components. So, several research questions arise. (1) How can the analysis of the semiotic potential and the need to support the instrumental genesis guide first the design of tasks for students and then the analysis of students' activities and teacher's didactical actions? The manipulation of the pascaline produces some gestures, that we call gesture of usage. They could be considered as visible parts of schemes (for instance, gestures - "accounts" in Trouche, 2004, p. 296). (2) Can relationships be identified between those gestures and signs (gestures as a part of systems of signs, Arzarello, Paola, Robutti \& Sabena, 2009; Maschietto \& Bartolini Bussi, 2009), with respect to mathematical meanings? In his work, Rabardel (1995) distinguishes kinds of schemes and their functions. From an educational viewpoint, two questions can be formulated. (3) Is the distinction between the three functions of utilisation schemes useful for the analysis of the teaching experiments? (4) Is the distinction between usage schemes and instrumented action schemes useful to the analysis of students' activities?

\section{EMPIRICAL RESEARCH METHODOLOGY}

According to the Theory of Semiotic Mediation, the pascaline is firstly analysed in terms of semiotic potential. Then different teaching experiments, carried out at different school levels, are discussed.

\section{Semiotic Potential of the pascaline}

The analysis of semiotic potential considers three components (Bartolini Bussi \& Mariotti, 2008): mathematical content, historical references and utilisation schemes.

With respect to the mathematical contents, the pascaline allows three- digit numbers in decimal positional notation to be represented: i.e. in Fig. 1b, wheel A represents units, wheel B tens and wheel C hundreds. The sequence of natural numbers can be generated by the iteration of the function " +1 " from the starting number zero, following Peano's (1858/ 1932) axiomatic (Peano, 1957-1959). This is the basis for making arithmetical operations.

Concerning historical and cultural references, there are clear links to the machine constructed by Blaise Pascal. Even if Zero+1 is not a reconstruction of the Pascaline, the two machines share some essential features, such as the gear-based structure, the decimal positional notation for representing numbers and the carry mechanism which allows for an effective propagation of multiple carries. The historical background of this tool allows the history of calculators and the need to automate the calculations to be introduced to the students, to convey the concept of machines being ,Äòfull of mathematics' human products.

The third component is to identify the possible utilisation ways. In this section, the expression "utilisation ways" will be used instead of "utilisation schemes" in order to stress the feature of a priori analysis that is carried out below. The latter expression will be reserved to the analysis of students' activity during the teaching experiments.

The pascaline has a very important feature: it does not have hidden components, as the gears are visible to the students, who can then observe all their movements and touch all the components. It has a starting state, corresponding to the configuration (000) over the red triangles.

Representing Numbers. Zero + 1 allows natural numbers until 999 to be represented in two ways: (1) turning wheel A one-tooth clockwise as many times as the number represents (writing by iteration); (2) units, tens and hundreds are identified in the chosen number to be represented; for each of them, writing by iteration is applied to wheels A, B and C, respectively (writing by decomposition). At the end of either of these actions, the number is read on the three teeth next to the red triangles (for instance, 620 in Fig. 1a).

A non-trivial question arises about this kind of number representation, as it requests acceptance of one or two heading " 0 " digits on the smaller numbers than ninety-nine (for instance, three is represented as "003"). 
Making Calculations. Zero +1 can be used to perform elementary arithmetical operations. Addition corresponds to the clockwise rotation of the lower yellow wheels, while subtraction to anticlockwise rotation. This structural difference strictly links the two operations. For instance, in order to calculate $12+25$, first of all the term 12 has to be represented. Then, two basic ways of completing the calculation can be executed: (1) wheel A is turned 25 times one-tooth clockwise (addition by iteration) or (2) the second term 25 is separated into units and tens, each of them is added by the rotation of wheels A (five times one-tooth clockwise) and B, respectively (two times one-tooth clockwise) (addition by decomposition). At the end, the result is read over the red triangles. These two utilisation ways are not equivalent. The size of the second term can lead to choose the second way (too many one-tooth rotations have to be performed). Further, the second way needs prior knowledge of the decimal positional notation. In general, other ways of making operations are possible, with respect to the specific tasks and student's knowledge (for instance, commutative property can be applied in the example in order to reduce number of one-tooth rotations). The machine Zero +1 introduces asymmetry in the output of user's actions for addition: all the two terms of the addition are written with the some kind of actions as specified above, but only the first number can be read on the pascaline at the beginning, while the second term can never be read on the machine. So it shows the first term, partial results and the final result.

Only one automatic movement is allowed in Zero +1 : at the clockwise rotation of a yellow wheel (A and B) from 9 to 0 , a jerk of the wheel next to it on the left (B and C) is produced, accompanied by a louder sound than the sound produced by the rotation of the tooth. In this case, the concurrent movement of the two wheels is particularly significant because it draws attention to the process of composition (decomposition) of a ten from units. For subtraction, this process is in reversed order. This machine however only works as a counter in base ten (adding machines); multiplication and division can only be made through repetition of addition and subtraction respectively. In this sense, Zero+1 is not an automatic machine for multiplication and division, and an external memory is necessary to take into account the number of iterations.

In the definition of the analysis of the semiotic potential of an artefact, a didactical analysis of this machine is not specifically presented, even if it has to be taken into account in order to establish the link between the artefact and personal meanings, by the means of tasks that are accessible to students. We consider some elements can be discussed in such a didactical analysis:

1. The machine emphasises the symbolic writing of numbers, where the zero digit has the same role of the other digits (and it does not correspond to an empty column as in the abacus). In particular, digits can be seen as labels for the teeth of the yellow wheels.

2. The structure of this machine highlights the relationships between addition and subtraction (the latter as the inverse of the former), that are, on the other hand, often presented in a separated way in mathematical textbooks. They are related by the opposite (and reversal) actions to construct and deconstruct a tens (or a hundreds), that is relevant from a didactic point of view.

3. Concerning division, the Zero +1 performs Euclidean division, where the residual has to be read on the machine, while the quotient has to be memorised in some way (paper and pencil, fingers, ...).

4. On the other hand, the machine has a point for decimal numbers, whose role has to be analysed with respect to students' difficulties with decimal numbers (for instance, a decimal number as a couple of natural numbers put one close to the other).

5. In our analysis of the semiotic potential, the analysis of machine feedback is important. The automatic movement can be considered a feedback if the number system is being built (the constitution of a tens by units). Another feedback is the following: if a student want to use Zero +1 to make addition, for instance, using a binary definition (the first term on wheel C, the second on wheel B and the result expecting on wheel A), Zero +1 does not work. Finally, the sound, when a tooth is turned and/or ten is made (and vice versa), is another relevant feedback.

\section{The Design of Teaching Experiments}

The analysis of the semiotic potential shows the pascaline addresses two essential contents in the mathematics curriculum in primary school: place value and arithmetical operations. Teaching experiments in the frame of mathematics laboratory thus mainly affect those school levels.

The theoretical background presented in the previous section supports the design of teaching experiments (and so the characterisation of a laboratory methodology) and its a priori analysis. We outline a part of this analysis as follows.

Following the Theory of Semiotic Mediation, the didactical structure consists of the succession of one or more didactical cycles, in which the first activity has to be carried out in small groups with the pascaline. The definition of the first task involves a facet of the first research question on task design. On the one hand, the 
instrumental approach suggests that the instrumental genesis has to be taken into account. On the other hand, the use of an artefact as a tool of semiotic mediation relies on how mathematical content is embedded in the structure of the artefact itself. We can answer to the first research question as follows. The two frameworks intertwine in a strong way. At the beginning of the didactical path, the activities with the pascaline can expressly support the instrumentalisation process in terms of making the components of the artefact emerge. In this case, Zero +1 is the object of the task (its analysis is the purpose of action for students) and is not the means to perform any specific tasks (i.e. writing numbers or making calculations). The work can be introduced in different manners, but the task (for instance, exploring the artefact, describing it, drawing it) has to foster the description of the pascaline in terms of structure and movements, related to a free manipulation of wheels. In such a way, user's actions can be interpreted as potential elements of usage schemes, corresponding to some gestures of usage. The analysis of the teaching experiments could provide other elements for this facet of the first research question.

After this phase of discovery of the pascaline, specific tasks related to the content of mediation can be proposed to the students. According to the instrumental approach, these solicit the development of instrumented action schemes (concerning the instrumentation process). If the teacher fosters the production of conjectures about how the pascaline works, the student's personal meanings are recalled, but also some utilisation schemes can be activated. In such a way, both their heuristic and epistemic functions can be promoted. But the latter mainly appears in collective moments following the group work.

The work of each group is followed by collective moments, where students share their exploration. A social construction of schemes can happen. Individual texts can be also requested by the teacher.

Several teaching experiments were carried out with the pascaline within the mathematics laboratory in primary school classes (Canalini Corpacci \& Maschietto, 2011; Casarini \& Clementi, 2010; Maschietto \& Ferri, 2007). This paper considers two kinds of teaching experiments (called Exp_A and Exp_B). The teachers involved in those teaching experiments belong to a university research group in mathematics education; the teacher of Exp_A had more experience than the others in managing mathematics laboratory classes.

Each teaching experiment was planned by the teachers of the classes with the researcher in terms of collaborative work. For each experiment, a grid was filled with a partial a priori analysis of the tasks for students (didactical cycles). Each session was videotaped and recorded by the researcher and the teachers. The analysis considers the comparison between the a priori analysis and the effective achievement in the classroom. It is based on the transcriptions of collective moments and mathematical discussions. It is enriched by video clips for the small group activities and collective moments, and by pupils' worksheets (texts and drawings) for individual activities.

The structures of the two teaching experiments considered in this paper are described below, and then analysed in the next section.

[Exp_A] It was carried out at the end of grade class 3 and at the beginning of grade class 4 in 2006 . When the experiment started, the pupils had knowledge of the four arithmetical operations and of the procedures to make calculations (for instance, column additions). Since grade 1, the teacher had proposed mathematical discussions and activities with artefacts (for instance, they had worked with spike abacus before the pascaline). The contents of mediation, following Hasan's definition, were:

(1) recursive principle to construct numbers and do operations related to the meaning of unary operation and (2) meaning of algorithm for arithmetical operations. The teaching experiment consisted in nine steps $(2 \mathrm{~h}$ per step), where two didactical cycles were performed (Maschietto \& Ferri, 2007). The steps were: [steps 1 ,Äì 4] group work for the discovery of Zero +1 , group work for the description of Zero +1 , mathematical discussion about addition, mathematical discussion on different utilisation schemes; [step 5] collective moment to recall work with Zero+1; [steps 6 - 8] individual writing of instructions to make addition and subtraction, mathematical discussion, collective comparison of instructions; [step 9] individual writing of the two utilisation schemes to make additions by the pascaline.

[Exp_B] Two teaching experiments were carried out by two teachers working together within a regional project of teacher education in mathematics laboratory (Casarini \& Clementi, 2010) at grade class 4 in 2010. The content of mediation, following Hasan's definition, was the decimal positional notation for both their classes. Each teaching experiment consisted in three steps ( $2 \mathrm{~h}$ per step). The steps were: (1) group work for the exploration of the pascaline, collective moments and individual drawings, (2) group work on worksheet presenting different incorrect representations of Zero+1, a collective discussion, the recon- struction of the pascaline by paper and paperclip, individual worksheets, (3) individual worksheets, collective discussion about utilisation schemes for writings numbers, individual worksheets. 


\section{THE ANALYSIS OF THE TEACHING EXPERIMENTS}

In this section, the first steps of Exp_A and Exp_B are analysed. Four phases are identified: exploration of Zero+1, utilisation schemes for writing numbers, utilisation schemes for making addition and mathemat- ical discussion on utilisation schemes.

\section{Exploration of Zero +1}

[Exp_A] At the beginning of step 1, the teacher introduced the pascaline to her class by telling the story of Blaise Pascal and his calculator (cultural and historical component). During the group work, two kinds of moments can be distinguished. The first one was related to the task "Observe it, try, and experiment", which fostered the beginning of the instrumentalisation process as the emerging of components of the pascaline. The second moment was defined by the task "Make calculations, in particular addition", corresponding to the instrumen- tation of Zero+1 (that is to the construction of instrumented action schemes for addition).

We analyse here the first moment. All the pupils acted on the artefact in an apparently random way ("Look, everything moves"). But this was important to discover the components, their relationships (gears train) and movement of rotation (that we call the "functioning principle"). These actions were associated with different gestures, that we have called gestures of usage. For instance, some students turned wheels D and E gripping the mauve arrows upon them (arrow gesture of usage, Fig. 2a) as a knob or a small lever; yellow wheels were also gripped by hand and turned (wheel gesture of usage, Fig. 2b). The use of fingers (in particular the forefinger) emerges afterwards (one-tooth-at-a-time gesture of usage) (Fig. 2c). The analysis of the semiotic potential emphasises that these gestures are not equivalent with respect to mathematical meanings: arrow gesture of usage could be performed for writing number, but it would create a conflict (for instance, inverse rotation of the corresponding yellow wheel) with respect to clockwise rotation for addition. Instead, the one-tooth-at-a-time gesture of usage is very relevant: it is acted to manage the pascaline and it is related to the mathematical meaning of ' 1 '. This is a first element of answer for the second research question.

The students also found that the movement of the wheel is not continuous but jerky and the movements of the wheels were linked together. In general, other static artefact components (as the red triangles and the point) were detected later, as well as the sound.
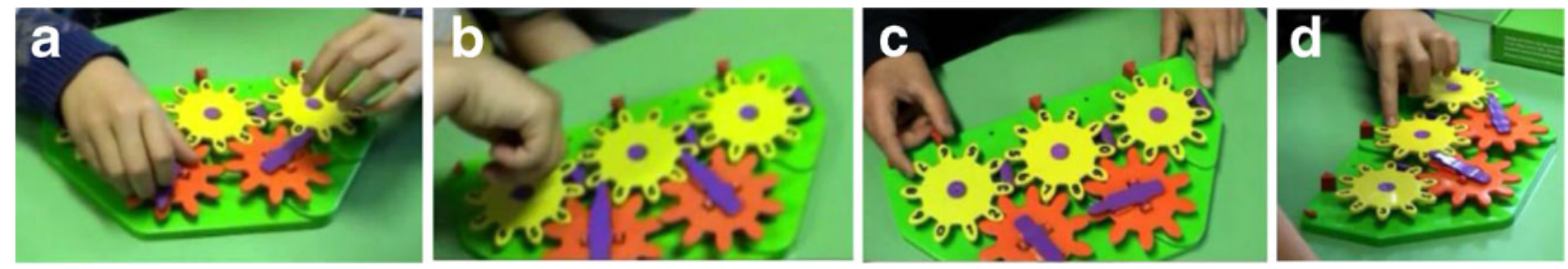

Figure 2. Usage and deictic gestures (Exp_A)

[Exp_B] The teachers characterised the first phase as a discovery of the pascaline in group work, with the aim to foster the formulation of conjecture about its functioning. In the collective moment that followed this group work, the students discussed the structure of Zero + 1 ("There are some gears", "Two orange [wheels] and three yellows ones. They have points with numbers from zero to nine. There are red triangles and one comma which we can move and mauve arrows") and shared some ideas about its functioning. They stressed the related movement of yellow wheels determined by the mauve arrows (over the orange wheel D and E),

the results of those movements ("And the number changes") and the two types of rotation of the wheels ("we can choose if we turn these numbers clockwise or in the other direction"). The teacher also asked the formulation of conjecture about the purpose of using Zero+1. The richness of students' proposition ("decoding the numbers", "counting", "finding the units", "making operations") pays attention to their personal meanings emerging in this first phase of work with the pascaline. Referring to the semiotic potential, this constitutes a facet of the double semiotic link of its definition. We remark that in students' proposition the finality of pascaline is present (Federico: "it serves to form the three-digit numbers"), but any instrumented action schemes is not present. On the other hand, in this discussion epistemic value for the use of pascaline emerged (MatteoV: "The pascaline serves to understand digit and numbers").

During the exploration, the pupils discovered the automatism of the pascaline, that is the number to be carried ("The arrow lowers when [the red triangle] is under the nine [tooth] and later I put the zero, the arrow 
makes turn the next wheel", "When I turned ten times, then [the mauve arrow] makes turn the next one", "When the zero arrives, the arrow makes turn the next wheel"). During the exploration and the collective discussion, the student produced situated texts, which represent a kind of starting point for teacher's mediation action toward mathematical meanings evoked by the use of Zero +1 . Even if there was not a specific instrumented action to perform by Zero +1 , this moment corresponds to a discovery and appropriation phase that is supposed to support the development of utilisation schemes to write and make calculations. On the other hand, MatteoV's speech pays attention to the presence of an epistemic dimension in the work with Zero +1 with respect to a pragmatic one (linked to technical instrument following Vygotsky).

According to the structure of the didactic cycle, the teacher proposed the individual activity of drawing the pascaline, which shows different levels of appropriation of the structure of the artefact (Fig. 3).

The analysis of the first phase shows the emergence of potential usage schemes and gestures of usage. This can be related to the fact that student's actions are not directed to the use of the pascaline. However, at the same time, those exploration tasks support the instrumentalisation process. The analysis of the semiotic potential of the pascaline allows discriminating among schemes and signs that are relevant from the mathematical content with respect to the object of mediation. The introduction of the activity and the first tasks seems to foster different ways to recall students' personal meanings.

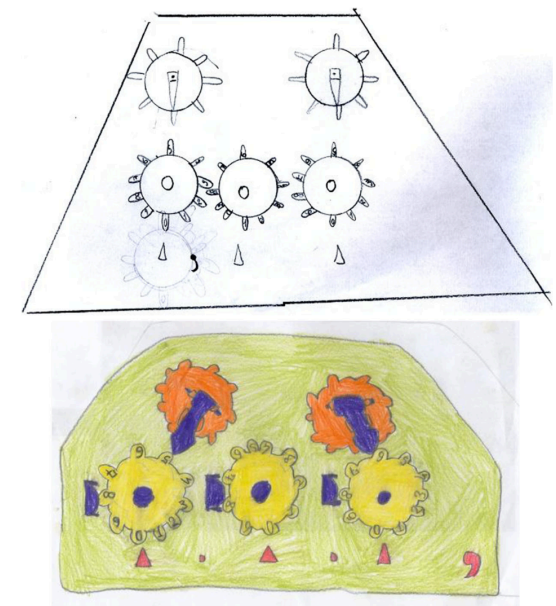

Figure 3. Drawings of Zero + 1 (Exp_B)

After the phase of discovery of Zero+1, the tasks focused on the instrumentation of the pascaline: the Exp_B considered writing of natural numbers; the Exp_A also considered arithmetical operations. We analyse the two cases in the next section.

\section{Utilisation Schemes for Writing Numbers}

[Exp_A] Writing numbers is an implicit but necessary task behind the given task to make addition, according to the analysis of the artefact. For the students, crucial elements were to discover how the rotation of a wheel leads to the movement of another wheel and the relationships between yellow wheels and red triangles, pointing to teeth with digits. For instance, student's deictic gestures on teeth corresponding to red triangles (Fig. $2 \mathrm{~d}$ ) stress the role of those teeth and support the interpretation of the role of wheels in writing numbers. When this kind of gesture was associated with the rhyme "units, tens, hundreds", writing numbers by decomposition was revealed. After mental decomposition of the number, the wheels were managed in order to show the respective digits. Apart from one group, most of the pupils succeeded in writing numbers on Zero +1 . In general, they acted on wheels using different kinds of gestures: in order to write a number, wheels were turned (with different gestures of usage) and the control of their movements was performed through tooth pointing by the red triangles. This utilisation scheme was not considered in our analysis of the pascaline. It is based on the decimal positional notation, but it does not seem to involve any control on how and many times the wheels are turned, but only a control over the red triangles with adjustments one following to the other. We call it "writing by controlling triangle" utilisation scheme. All the gestures of usage identified in the previous phase could be considered parts of the constituent related to the usage schemes. Writing by iteration did not appear during this moment.

[Exp_B] After drawing and reconstructing the pascaline with paper, the third step consisted in an individual work proposed by a worksheet with the task to write the number 13 on Zero+1 and to explain how to do it. In 
terms of instrumental genesis, this kind of request seems to foster the epistemic function of utilisation schemes, not only pragmatic one. In the discussion following this work, the teacher aimed at social construction of utilisation schemes for writing numbers.

In pupils' worksheets, both utilisation schemes of writing by iteration (excerpts 1 and 2) and by decomposition (excerpts 3 and 4) appeared, even if the latter was the most chosen.

Excerpt 1. To reach the number 13 it needs to turn the first yellow gear [wheel] on the right. To reach the number 1 it is necessary to make a [complete] turn to the first gear [wheel] in such a way that in the second gear [wheel] the [digit] 1 goes off and then the first gear [wheel] turns again on 3 and all is ok.

Excerpt 2. The first yellow small wheel must be turned and changes the number, you must turn it at least 13 times clockwise and [the number] 13 is formed on the small engine $0+1$.

Excerpt 3. To write the number 13 you have to put three in the unities [last wheel on the right] turning clockwise and [put] the number one in tens [wheel] [wheel at the middle] and so you have number 13.

Excerpt 4 To put the number 13 on the machine it needs that in the gear [wheel] below on the right you move the tooth with the number 3 where the red triangle is. To put the number 1 you have to move the gear [wheel] below at the centre, to move it clockwise until 1 appears. The last gear [wheel] must be left on 0 .

These two excerpts pay attention to:

1. Reference, or not, to the direction of rotation of wheels: the direction is yet implicit in excerpt 1 , while excerpts 2 and 3 contain this information.

2. The names of the components (teeth, wheel) with respect to their mathematical meanings: the pupils used "gears" in a general way, but they also connected the different wheels to their roles in writing number (excerpt 2).

3. Reference to automatism of Zero +1 is present in Excerpts 1 and 2.

4. Implicitness of 000 as being the initial state in all the excerpts.

Excerpts 3 and 4 seem to contain the utilisation scheme for writing appeared also in Exp_A.

\section{Utilisation Schemes for Making Addition}

As presented in the design section, only Exp_A contained tasks for making arithmetical calculations.

In order to make addition, the students had different kinds of difficulty; some of them are summarised in the following excerpt in terms of instrumental genesis.

1. Teacher: What number do you write? What operation do you want to do?

2. ChiaraP: With plus.

3. Teacher: Tell me one.

4. ChiaraP: Seven hundred plus sixteen.

5 Teacher: Seven hundred plus sixteen. And how do you write seven hundred?

Michael wrote 716 with Zero +1 . The teacher looked at it.

6 Teacher: But you have already written the result! Because you knew it by heart. I ask you ... Michael said an operation ... maybe seven hundred plus.

Michael turned the wheels to show 700. After a few minutes, the teacher said:

7 Teacher: You had said seven hundred plus.

8 Michael: Sixteen.

9 Teacher: How do you do it? That is what I'm asking ... Michael turned wheels in a controlled way.

In this excerpt, the teacher invited the students to choose an operation to do (\#1), which completed the tasks of the session. They adopted a strategy grounded on the utilisation scheme to represent numbers and changed the required task into a new task which was "make a mental calculation and represent the result". When the teacher invited to use the pascaline (\#6), the students came back to the writing. After another question (\#9), counting teeth was considered in their strategy: rotation was now controlled in order to obtain the result (mentally calculated), namely to read it above the red triangles. The first solution (\#1 - 6) can be interpreted in terms of conflict between the utilisation scheme of writing by controlling triangles for all the two terms of the addition and the analysed features of the pascaline with respect the output for those terms. Writing by controlling triangles seems to introduce an asymmetry for the two numbers of addition in terms of gestures of usage: the second number could not be written following this scheme, but it requires the one-tooth- at-a-time gesture of usage. So, the students had to activate it in order to make the addition as requested by the teacher. 
They started to conjecture about the rotation direction of the wheels and operations (addition and subtraction) acting on yellow wheels. After this, they tried to do other additions by decomposition to check their strategy and make it stable. With respect to gestures, arrow gesture of usage and wheel gesture of usage began to be progressively left, and the one-tooth-at-a-time gesture of usage often appeared.

Other students had the same difficulties, but they did not succeed in transferring the computation to the pascaline, or adapting their schemes to the features of the machine (Maschietto \& Ferri, 2007). For one group, the knowledge of binary operations blocked the construction of an instrumented action scheme for operations with Zero+1, because it guided it towards a wrong strategy: writing the two numbers to be summed and reading the result (to write on wheels $\mathrm{C}$ and $\mathrm{B}$, and to wait for the result on wheel $\mathrm{A}$ ). The feedback of Zero+1 is difficult to interpret and to use it in order to change strategy.

\section{Mathematical Discussion on Utilisation Schemes}

In the third step of Exp_A, the teacher takes into account the evolution of signs produced during the activity with the artefact (situated texts) towards mathematical meanings and texts. This collective phase support- ed once more instrumental genesis, mainly from the viewpoint of the social construction of utilisation schemes. Even if one of teacher' first statements highlighted the pragmatic function of the utilisation schemes, during the discussion the teacher aims to stress the epistemic function of the utilisation schemes, which may be relevant for students' internalisation processes. She tried to raise the implicit knowledge in the schemes, with respect to the content of mediation. At the same time, she also promoted the evolution of utilisation schemes (instrumentation); for instance, she took into account the initial configuration of the wheels. The evolution of meanings related to these signs was carried out through the proposal of some operations, which allowed students to make their utilisation schemes stable. Some steps are considered below.

The teacher wrote an addition on the blackboard and proposed to make it by Zero+1. With respect to the already analysed Exp_B, writing numbers seemed to have a state of usage scheme. In a sense, that it is a necessary step to make the operation and it is not the core of the given task at the beginning of the session. With respect to the research questions, the distinction of the constituents of schemes allows characterising the kind of tasks for students.

Afterwards, when the kind of operation to be done was told, a fundamental component of the utilisation schemes appeared, related to unary operation: the word "plus" or the sign "+" did not correspond to any action on Zero+1. So it emerges that in the process of doing operations with Zero+1, actions for " $143+29$ " correspond to the expression "firstly '143' then '29'"; in addition, the procedure leads to change the first term that has already been represented (coherently with "counting on" and actions on line numbers met at grade class 1). A student, Orlando, highlighted the cognitive process related to "do '+"' ("And in the meantime we have to think about something: how does the wheel turn to add? Clockwise or anticlockwise? That one is not performed by the machine, you think about it!").

When the second term was given, a germ of addition by iteration appeared by a student (with several implicit elements), but the class performed the other utilisation scheme. Addition by iteration is presented in the synthesis of the two utilisation schemes suggested by Orlando. Even if he was bound to a description of actions on the pascaline in a pragmatic way, containing several spatial references for the wheels, he seemed to introduce a scientific conceptualisation (following Vygotsky, 1934/1990) on Zero + 1 into the discussion. He justified the equivalence of the two schemes in terms of the number to be carried ("You obtain the same result because of the number to be carried by the other arrow [he indicates wheel D] that moves the tens [wheel] twice ..."). After this, some students compared the two schemes in terms of conveniences in doing addition (number of one-tooth-ata-time gestures). The utilisation schemes seem to show their heuristic function, leading them to anticipate possible and impossible actions. The sequence of operations given by the teacher serves not only to consolidate the utilisation schemes, but also to make new properties and theorem-in-action emerge.

During the first part of the discussion, the students were still talking about the description of wheel position, while the teacher fostered the specification of the place value of the wheels, trying to change students' pragmatic sentences into epistemic ones (e.g. "why [do you put] two on the second wheel?"). These requests for argumentation solicited the students to create links between their utilisation schemes and mathemat- ical knowledge (i.e. place value). The automatic movement of the machine was detected, but at this point, few students managed to explain the functioning of Zero +1 from an epistemic viewpoint with reference to number to be carried and, so decimal positional notation. The compe- tences of these students on notation also appeared in their interpretations of other students' wrong strategies and in the justification of the mathematical equivalence of the schemes.

With respect to gestures of usage, by this collective discussion the students definitely abandoned both the arrow gesture of usage and wheel gestures of usage and considered one-tooth-at-a-time one (right forefin- ger), 
related to recursive meaning. The linguistic expressions were increased, always situated in the activity with the artefact. In several statements, the one-tooth-at-a-time gesture of usage for all the units or for units and tens was related to linguistic expressions like "turn [n] times" and "turn the wheel [n] times", that evokes the idea of iteration but does not correspond to the realistic action on the wheel (there is mismatch between gestures and speech, Church \& Goldin-Meadow, 1986). The meaning of "times" is contextualised to the artefact and forced by the jerky movement. This expression, rooted in the iteration of the one-tooth- at-a-time gesture of usage, becomes fundamental in the passage to mathematical texts.

\section{DISCUSSION}

The analysis of the experimentations allows dealing our first research question focusing on the relationships between the semiotic potential of the pascaline and students' instrumental genesis. This represents an example of how the analysis of the artefact supports the definition of tasks for students fostering the emergence of mathematical meanings. At the same time, the theoretical tools of the instrumental approach allow taking into account the cognitive processes of the students involved in the activities with the pascaline. The analysis of the semiotic potential also gives elements to distinguish among the different potential schemes or strategies to solving tasks and identify which schemes should be reinforced (related to the mathematical contents at stake).

By analysing the teaching experiments, the identification of the function of the utilisation schemes was useful to characterise teachers' choices and students' interventions. Even if in the first steps of the teaching experiments, the teachers seemed to focus on the development of utilisation schemes to perform tasks (pragmatic function), their educational aim has never had the construction of a technical tool (related to the pragmatic function). In this sense, epistemic and heuristic functions of utilisation schemes were also solicited. The tasks and teacher's questioning wanted to bring the students to make such schemes explicit, and above all to make them transparent with respect to the knowledge behind the schemes (that it is often the content of mediation). From this perspective, this paper gives some elements to our third research question, deepening an aspect of the work by Maschietto \& Trouche (2010).

Concerning the research question 2 on identifying gestures and visible parts of schemes, some gestures (called gestures of usage) emerge in the students' activity with the pascaline. The analysis shows that the contents of mediation (the recursive definition of the operation and place value) is rooted in a particular gesture, called one-tooth-at-a-time gesture of usage, and that the collective discussions lead to abandon the other gestures and reinforce some expressions supporting mathematical meanings. Taking the semiotic activity promoted by the instrumented actions into account allows to identify how the use of Zero +1 creates and supports the meaning of linguistic expression "turn n times", which is also related to iteration. The consolidation of the utilisation schemes, the request for formulation and argumentation foster the construction of mathematical meanings.

The analysis of the resolution of different tasks (writing numbers and making operations) proves that in order for a scheme to be identified either as a usage one, or as an instrumented one, depends on the task. This is the topic of the fourth research question. This distinction seems to allow students' cognitive processes and difficulties to be interpreted. That analysis also enriches the study of the pascaline and its semiotic potential showing the emergence of new utilisation schemes (for instance, writing by controlling triangles).

The didactic structure of the teaching experiments allows supporting processes of instrumental genesis, on an individual level but above all on a social level, in accordance with the strong cultural dimension and the importance of the role of teacher in the Theory of Semiotic Mediation.

Finally, from the viewpoint of the networking strategies, further study of the coordination between the two theoretical frameworks will be addressed. This paper improves some elements discussed in (Maschietto \& Trouche, 2010); it does not take into account some other relevant questions that need to be studied, such as the construction of systems of instruments (when Zero +1 is combined with other instruments construct- ed by the students) in terms of both cognitive constructions and didactical management, and teacher's action in terms of instrumental orchestration.

\section{ACKNOWLEDGMENTS}

I wish to sincerely thank the teachers R. Canalini, A. Casarini, F. Clementi and F. Ferri, and the anonymous referees for their precious suggestions. 
Maschietto, M. (2015). The arithmetical machine Zero+1 in mathematics laboratory: instrumental genesis and semiotic mediation. International Journal of Sciences and Mathematics Education, 13 (Suppl 1), 121-144. DOI: 10.1007/s10763-013-9493-x

\section{REFERENCES}

AA.VV. UMI (2004). In G. Anichini, F. Arzarello, L. Ciarrapico \& O. Robutti (Eds.), Matematica 2003. La matematica per il cittadino. Lucca: Matteoni stampatore.

Artigue, M. (2002). Learning mathematics in a CAS environment: the genesis of a reflection about instrumentation and the dialectics between technical and conceptual work. International Journal of Computers for Mathematical Learning, 7, 245-274.

Arzarello, F. Paola, D., Robutti, 0. \& Sabena C. (2009). Gestures as semiotic resources in the mathematics classroom. In L. Edwards, L. Radford \& F. Arzarello (Eds.), Educational Studies in Mathematics 70(2), 97-109.

Bartolini Bussi, M.G. \& Borba, M. (Eds), (2010). Historical aspects of the use of technology and devices in ICMEs and ICMI. ZDM The International Journal on Mathematics Education, 42 (1).

Bartolini Bussi, M. G. \& Mariotti, M. A. (2008). Semiotic mediation in the mathematics classroom: artifacts and signs after a Vygotskian perspective. In L. English (Ed.), Handbook of int. research in mathematics education (2nd ed., pp. 746-783). New York: Routledge.

Béguin, P. \& Rabardel, P. (2000). Designing for instrument-mediated activity. Scandinavian Journal of Information Systems, 12, 173-190.

Canalini Corpacci, R. \& Maschietto, M. (2011). Gli artefatti-strumenti e la comprensione della notazione posizionale nella scuola primaria. La 'pascalina' Zero+1 nella classe: genesi strumentale. L'Insegnamento della Matematica e delle Scienze Integrate, 34A(2), 161-188.

Casarini, A. \& Clementi, F. (2010). Numeri... in macchina: alla scoperta della pascalina. In USR E-R, ANSAS E-R, Regione Emilia-Romagna \& F. Martignone (Eds.), Scienze e Tecnologie in Emilia-Romagna, vol. 2. Napoli: Tecnodid Editrice, 141-145.

Chiappini, G. \& Reggiani, M. (2004). Toward a didactic practice based on mathematics. In M.A. Mariotti (Ed.), Proceedings of CERME 3. http://www.dm.unipi.it/ didattica/

CERME3/proceedings/Groups/TG9/TG9_Chiappini_cerme3.pdf. Accessed May 2013.

Church, R. B. \& Goldin-Meadow, S. (1986). The mismatch between gesture and speech as an index of transitional knowledge. Cognition, 23, 43-71.

Drijvers, P., Kieran, C. \& Mariotti, M. A. (2010). Integrating technology into mathematics education: theoretical perspectives. In C. Hoyles \& J.-B. Lagrange (Eds.), Mathematics education and technology-rethinking the terrain (pp. 89-132). New York: Springer.

Giacardi, L. (2012). The emergence of the idea of the mathematics laboratory at the turn of the twentieth century. In K. BjarnadoÃÅttir, F. Furinghetti, J. M. Matos \& G. Schubring (Eds.), "Did where you stand” 2, Proceedings of the Second Int. Conference on the History of Mathematics Education (pp. 203-225). Caparica: UIED.

Hasan, R. (2005). Semiotic mediation, language and society: three exotripic theories- Vygotsky, Halliday and Bernstein. In J. Webster (Ed.) Language, society and consciousness: the collected works of Ruqaya Hasan, vol 1. London: Equinox. http:// lchc.ucsd.edu/mca/Paper/JuneJuly05/HasanVygHallBernst.pdf. Accessed May 2013.

Hoyles, C. \& Lagrange, J.-B. (Eds.). (2010). Mathematics education and technology: rethinking the terrain. New York: Springer.

Mariotti, M. A. (2012). ICT as opportunities for teaching-learning in a mathematics classroom: the semiotic potential of artifacts. In T. Y. Tso (Ed.), Proc. of the 36th Conference of the International Group for the Psychology of Mathematics Education (Vol. 1, pp. 25-40). Taipei: PME.

Maschietto, M. (2011). Instrumental geneses in mathematics laboratory. In B. Ubuz (Ed.), Proc. of the 35th Conference of the International Group for the Psychology ofMathematics Education (Vol. 3, pp. 121-128). Ankara: PME.

Maschietto, M. \& Bartolini Bussi, M. G. (2009). Working with artefacts: gestures, drawings and speech in the construction of the mathematical meaning of the visualpyramid. Educational Studies in Mathematics, 70(2), 143-157.

Maschietto, M. \& Ferri, F. (2007). Artefacts, schèmes d'utilisation et significations arithmètiques. In J. Szendrei (Ed.), Mathematical activity in classroom practice and as research object in didactics: two complementary perspectives, Proceeding of the CIEAEM 59, Dobogoko, Hungary. 179,Äì183. http://math.unipa.it/ grim/. Accessed May 2013.

Maschietto, M. \& Trouche, L. (2010). Mathematics learning and tools from theoretical, historical and practical points of view: the productive notion of mathematics laboratories. ZDM The International Journal on Mathematics Education, 42(1), 33-47.

Norman, D. A. (1993). Things that make us smart. London: Addison-Wesley.

Peano, G. (1957/1959). Opere scelte. In Ugo Cassina (Ed.). Roma: Cremonese. 
Prediger, S., Bikner-Ahsbahs, A. \& Arzarello, F. (2008). Networking strategies and methods for connecting theoretical approaches: first steps towards a conceptual framework. ZDM The International Journal on Mathematics Education, 40, 165-178.

Rabardel, P. (1995/2002). Les hommes et les technologies. Une approche cognitives des instruments contemporains. Paris: Armand Colin. (English version: (2002). People and technology. A cognitive approach to contemporary instruments. http://ergoserv.psy.univ-paris8.fr/. Accessed May 2013).

Savioli, K. (2005). Punti di forza per l'utilizzo della pascalina "Zero+1" in classe. Rassegna dell'istruzione, N. 1-2, 36-37. http://www.rassegnaistruzione.it/rivista/ index.html. Accessed May 2013.

Trouche, L. (2004). Managing complexity of human/machine interactions in computerized learning environments: guiding student's command process through instrumental orchestrations. International Journal of Computers for Mathematical Learning, 9(3), 281-307.

Trouche, L. \& Drijvers, P. (2010). Handheld technology for mathematics education: flashback into the future. ZDM The International Journal on Mathematics Education, 42(7), 667-681.

Vérillon, P. \& Rabardel, P. (1995). Cognition and artifacts: a contribution to the study of thought in relation to instrument activity. European Journal of Psychology of Education, 9(3), 77-101.

Vygotsky, L. S. (1934/1990). Myšlenie i reč’ Psichologičeskie issledovanija (Italian version: (1990). Pensiero e linguaggio. In L. Mecacci (Ed.). Bari: Laterza). 